\title{
Pengaruh Pendidikan Pelatihan, Pengalaman Kerja, Dan Prestasi Kerja Terhadap Pengembangan Karir Karyawan Pada PDAM Kabupaten Buleleng
}

\author{
Putu Dewi Supeni*1, I Nyoman Sujana ${ }^{2}$ \\ 1,2Prodi Pendidikan Ekonomi \\ Universitas Pendidikan Ganesha \\ Singaraja, Indonesia
}

e-mail: dewisupeni0912@gmail.com*1,nyoman.sujana@undiksha.ac.id²

\begin{abstract}
Riwayat Artikel Tanggal diajukan: 22 Juni 2021

Tanggal diterima : 23 November 2021

Tanggal dipublikasikan: 15 Desember 2021

Abstrak

Tujuan dalam penelitian ini ialah untuk mengetahui hubungan pendidikan dan pelatihan, pengalaman kerja, dan prestasi kerja terhadap pengembangan karir karyawan pada PDAM Kabupaten Buleleng. Penelitian menggunakan jenis penelitian kausal. Populasi dalam penelitian ini seluruh karyawan PDAM ialah 129 responden yang dicari menggunakan Non Probability Sampling atau sampel sensus. Metode dalam pengumpulan data yang digunakan menggunakan angket. Teknik analisis data yang digunakan yaitu analisis regresi linier berganda, uji t, dan uji F. Hasil penelitian menunjukkan bahwa terdapat pengaruh secara parsial dan simultan pendidika pelatihan, pengalaman kerja, serta prestasi kerja terhadap pengembangan karir karyawan karyawan pada PDAM Kabupaten Buleleng.
\end{abstract}

Pengutipan:

Supeni,P.D. \&

Sujana, I.N.

(2021) Pengaruh

Pendidikan

Pelatihan,

Pengalaman

Kerja Dan

Prestasi Kerja

Terhadap

Pengembangan

Karir Karyawan

Pada PDAM

Kabupaten

Buleleng. Jurnal

Pendidikan

Ekonomi

Undiksha, 13(2),

352-356

http://dx.doi.org/1

$0.23887 /$ ijpe.v13i

2.35775

Kata Kunci: Pendidikan dan Pelatihan; Pengalaman Kerja; Prestasi Kerja; Pengembangan Karir

\begin{abstract}
This study aimed at determining relationship of education and training, work experience, and work performance to the career development of employees at PDAM Kabupaten Buleleng. This research uses causal research. The population in this study, all PDAM employees, were 129 respondents who were sought using Non Probability Sampling or census samples. The method of data collection used was a questionnaire. The data analysis technique used is multiple linear regression analysis, $t$ test, and $F$ test. The results show that there is a partial and simultaneous influence of education, training, work experience, and work performance on the career development of employees at PDAM Kabupaten Buleleng.
\end{abstract}

Keywords : Education and Training; Work Experience; Work Performance; Career Development 


\section{PENDAHULUAN}

Sumber daya manusia bermutu merupakan sumber dayamanusia yang mempunyai keterampilan, keahlian, pengetahuan serta perilaku baik didalam bekerja. Karyawan yang bekerja di suatu perusahaan tentu menginginkan kenaikan dalam karirnya. Pengembangan karir sangat berarti untuk karyawan serta perusahaan, sebab terdapat interaksi serta pertumbuhan perusahaan itu sendiri lewat karir karyawan. Dalam meningkatkan pengembangan karir karyawan, perusahaan sebaiknya mencermati kebutuhan karyawannya. Ada pula wujud atensi yang biasa diberikan oleh perusahaan kepada karyawannya, salah satunya dengan melakukan pendidikan serta pelatihan yang baik sesuai dengan kebutuhan karyawan, adil dalam pemilihan pegawai yang mempunyai pengalaman kerja yang lama, serta membagikan apresiasi kepada prgawai yang memiliki prestasi kerja yang bagus.

Pendidikan elatihan bagian dari investasi sumber daya untuk meningkatkan kemampuan dan keterampilan kerja karna dapat meningkatan karir karyawan (Mangkunegara, 2004). Pendidikan pelatihan merupakan proses, tehnik, dan metode belajar mengajar untuk mentransfer pengetahuan dari seseorang kepada orang lain dan berhubungan dengan peningkatan pengetahuan umum dan pemahaman atas lingkungan yang dilakukan perusahaan. Pengalaman kerja ialah sebuah hal penting dalam peningkatan karir di suatu organisasi. Menurut (Foster, 2001) terdapat beberapa indikator yang menjadi pengalaman kerja yaitu Kelancaran pekerjaan adalah sejauh mana pegawai tersebut dapat melakukan pekerjaannya dengan baik dan lancar dikarenakan pengalaman kerja yang dimilikinya. Peningkatan prestasi kerja adalah output yang dihasilkan karena pengalaman kerja yang dimiliki mengakibatkan prestasi kerja pegawai menjadi meningkat. Penyelesaian tugas tanpa menunggu perintah berkaitan dengan pengalaman yang dimilikinya. Semakin berpengalaman pegawai tersebut, maka dian akan mampu menyelesaikan tugas tanpa menunggu perintah lagi dari atasannya. Tanggung jawab pada tugasnya.
Semakin berpengalaman, maka semakin mampun pegawai tersebut bertanggung jawab terhadap pekerjaan yang dibebankan kepadanya. Hasibuan (2015) menyebutkan "dalam suatu organisasi, prestasi kerja biasanya dikaitkan dengan usaha penentuan nilai suatu pekerjaan. Dengan adanya penilaian prestasi kerja pegawai maka pemimpin perusahaan dapat mengetahui tingkat potensi dan kemampuan yang ada pada masing-masing pegawai yang akan menjadi salah satu pertimbangan dasar bagi pemimpin dalam memberikan kompensasi, penempatan, promosi dan mutasi”. (Mangkunegara, 2004) mengatakan bahwa "prestasi kerja adalah hasil kerja secara kualitas dan kuantitas yang dicapai oleh seorang pegawai dalam melaksanakan tugasnya sesuai dengan tanggung jawab yang diberikan kepadanya, hasil kerja secara kualitas dan kuantitas yang dicapai oleh pegawai dalam melaksanakan tugasnya sesuai dengan tanggung jawab yang diberikan kepadanya itulah yang dimaksud dengan prestasi kerja". Hasil wawancara bersama Kepala Sub Bagian Umum serta sebagian karyawan PDAM Kabupaten Buleleng diperoleh data bahwa perusahaan kurang mengasosialisasikan program pendidikan serta pelatihan, hingga menimbulkan tidak jelasnya program dan aturan, terutama program tersebut kurang dioptimalkan pelaksanaanya serta harusnya diutamakan untuk karyawan yang masa kerjanya yang tergolong baru. Serta bagi sebagian karyawan materi program yang diberikan tidak sesuai dengan pekerjaan karyawan. Masih kurang baiknya peningkatan karir karyawan, terdapat karyawan yang waktu kerjanya lama (melebihi 6 tahun) tidak mendapatkan peningkatan jabatan di karirnya, permasalahan ini diakibatkan kurangnya informasi dan pengetahuan pertumbuhan karir mereka, dan prestasi kerja yang dirasa kurang untuk karyawan untuk bisa meningkatkan karirnya. Dari sebagian permasalahan dapat disimpulkan bahwa PDAM Kabupaten Buelelng dalam kenaikan karir karyawannya masih rendah dilihat dari masih banyak nya karyawan yang mempunyai masa kerja yang lumayan ataupun lama tetapi tidak mendapatkan 
peningkatkan dalam karirnya, tidakjelasnya program pendidikan dan pelatihan yang menyebabkan karyawan susah untuk menguasai materi serta penjelasan dari program tersebut dan minimnya kesempatan untuk karyawan baru ataupun yang masa kerja masih sedikit untuk mengikuti program tersebut sehingga menyebabkan minimnya prestasi kerja karyawan untuk meningkatkan karirnya. Penelitian Muis (2009) menyatakan diklat berpengaruh positif terhadap peningkatan karir. Penelitian lain juga mengemukakan masa kerja berpengaruh signifikan terhadap peningkatan karir (Jayanti, 2013). Prestasi kerja mempunyai pengaruh dominan dalam pengembangan karir (Labbase, 2010) Tujuan penelitian ini ialah untuk mengetahui pengaruh pendidikan serta pelatihan, pengalaman kerja, prestasi kerja secara parsial serta secara simultan terhadap pengembangan karir karyawan.

\section{METODE}

Penelitian kausal digunakan untuk membuktikan hubungan sebab akibat beberapa variabel. Populasi dalam penelitian ini adalah 129 orang karyawan pada PDAM Kabupaten Buleleng. Teknik pengambilan sampel dalam penelitian ini menggunakan Non Probability Sampling dengan menggunakan sampel jenuh atau sampel sensus. Sampel yang digunakan dalam penelitian ini seluruh populasi yaitu 129 orang responden. Metode pengumpulan data yang digunakan dalam penelitian ini yaitu metode angket dengan pengumpulan data melalui penyebaran kuesioner yang digunakan untuk mengambil data variabel pendidikan pelatihan, pengalaman kerja prestasi kerja, dan pengembangan karir. Analisis data yang digunakan dalam penelitian ini adalah analisis regresi linear berganda, uji t, uji $F$ dan uji asumsi klasik. Dalam hal ini hasil perhitungan akan diuji melalui hasil perhitungan SPSS For Windows 20.0.

\section{HASIL DAN PEMBAHASAN}

Berdasarkan hasil analisis data pengujian hipotesis dilakukan pada taraf $5 \%$. Adapun hasil uji t nampak pada tabel 1 dan uji F nampak pada tabel 2.

Tabel 1. Hasil Uji Parsial Pendidikan serta Pelatihan, Pengalaman Kerja, dan Prestasi Kerja Coefficientasa

\begin{tabular}{|c|c|c|c|c|c|c|}
\hline \multirow{3}{*}{ Model } & \multirow[b]{3}{*}{ (Constant) } & \multicolumn{2}{|c|}{$\begin{array}{l}\text { Unstandardizeed } \\
\text { Coefficiients }\end{array}$} & \multirow{2}{*}{$\begin{array}{c}\begin{array}{c}\text { Stndardized } \\
\text { Coeficients }\end{array} \\
\text { Beta }\end{array}$} & \multirow{3}{*}{$\begin{array}{l}\mathrm{t} \\
6,394\end{array}$} & \multirow{3}{*}{$\begin{array}{l}\text { Sig. } \\
, 000\end{array}$} \\
\hline & & B & Std. Eror & & & \\
\hline & & 15,874 & 2,483 & & & \\
\hline & $\begin{array}{l}\text { Pendidikan dan } \\
\text { Pelatihan }\end{array}$ & ,286 & 054 & ,364 & 5,257 &, 000 \\
\hline & $\begin{array}{l}\text { Pengalaman } \\
\text { Kerja }\end{array}$ & , 110 & 052 & , 191 & 2,102 & 0 \\
\hline & Prestasi Kerja & ,252 & ,066 & ,336 & 3,845 &, 00 \\
\hline
\end{tabular}

a. Dependent Variable: Pengembangan Karir

Sumber: Data diolah

Tabel 2. Hasil Uji Simultan Pendidikan serta Pelatihan, Pengalaman Kerja, Prestasi Kerja

\begin{tabular}{|c|c|c|c|c|c|c|}
\hline \multicolumn{7}{|c|}{ ANOVA $^{a}$} \\
\hline $\begin{array}{l}\text { Model } \\
1\end{array}$ & Regresion & $\begin{array}{l}\text { Sum of } \\
\text { Squaras } \\
607,570\end{array}$ & df & $\begin{array}{l}\text { Mean } \\
\text { Squaree } \\
202,523\end{array}$ & $\begin{array}{l}F \\
48,904\end{array}$ & $\begin{array}{l}\text { Sig. } \\
\quad 000^{\mathrm{b}}\end{array}$ \\
\hline & Residual & 517,655 & 125 & 4,141 & & \\
\hline & Total & 1125,225 & 128 & & & \\
\hline
\end{tabular}


Hasil dari tabel 1. dapat dijelaskan pengujian uji $\mathrm{t}$ dalam variabel pendidikan dan pelatihan didapat nilai sig 0,000 , pengalaman kerja memiliki nilai sig 0,038 dan variabel prestasi kerja didapat nilai sig 0,000 dimana yang berarti nilai sig ketiga variabel tersebut lebih kecil dari 0,05 maka dari ketiga variabel tersebut disimpulkan hipotesis $\mathrm{H}_{\mathrm{a}}$ diterima. Maka berarti terdapat pengaruh ketiga variabel tersebut secara parsial terhadap pengembangan karir.

Dilihat pada tabel 2 , didapat nilai $F$ hitung 48,904 atau nilai sig 0.000 lebih kecil dari 0.05 berarti $\mathrm{H}_{a}$ diterima. Dimana merupakan terdapat diklat, pengalaman kerja, dan prestasi kerja memiliki pengaruh secara simultan terhadap pengeembangan karir. Untuk menegtahui besarnya pengaruh, maka dapat dilakukan analisis koefisien determinasi. Nilai Adjusted $R$-Square sebanyak 0,529 menunjukkan ketiga variabel independen terhadap variabel pengembangan karir $52,9 \%$ dan sisanya $47,1 \%$ dipengaruhi oleh variabel lain.

Berdasarkan koefisien determinasi. dibuat model persamaan regresi $Y=15,874$ $+0.286 X_{1}+0,110 X_{2}+0,252 X_{3}$. Interpretasinya ialah besarnya nilai kostanta 15,874 artinya besarnya variabel tersebut memiliki pengaruh terhadap variabel pengembangan karir. Nilai koefisien $\mathrm{X} 1$, sebesar 0,286 menunjuk bahwa setiap peningkatan pendidikan serta pelatihan sebanyak 1 persen maka pengembangan karir meningkat 0,286 . Nilai koefisien X2 sebanyak 0,110 bahwa setiap peningkatan pengalaman kerja sebesar 1 persen maka pengembangan karir meningkat 0,110 . Dan nilai koefisien $\mathrm{X} 3$, sebanyak 0,252 menunjuk setiap peningkatan prestasi kerja 1 persen maka pengembangan karir meningkat 0,252 .

Berdasarkan hasil penelitian yang berbicara masalah pendidikan serta pelatihan tentunya memiliki pengaruh besar dalam pengembangan karir karyawan. Berdasarkan hasil riset disimplkan pendidikan serta latihan mempunyai pengaruh yang signifikan trhadap pengembangan karir. Didukung oleh teori dari (Gorda, 2004) menyatakan diklat ialah faktor dominan yang mempengaruhi pengembangan karir dan sebagai proses kegiatan untuk membetulkan dan meningkatkan pengetahuan serta kecerdasan sesuai keinginan dari organisasi yang bersangkutan. Temuan ini sejalan dengan hasil riset Muis (2009) menyebutkan pndidikan serta pelatihaan mempunyai pengaruh signifikan terhadap pengembangankarir. Artinya semakin sering pegawai diberikan peluang mengikuti diklat maka pengembangan karir karyawan PDAM Kabupaten Buleleng dapat meningkat dengan baik. Jadi dapat disimpulkan bahwa semakin karyawan diberikan peluang untuk mengikuti pendidikan pelatihan dengan baik akan berdampak kepada meningkat atau semakin baik pengembangan karir karyawan. Peneliian menunjuk hasil pengalaman kerja berpengaruh positif terhadap karir, maksudnya bila masa kerja pegawai lama maka peluang untuk peningkatan karir karyawan PDAM Kabupaten Buleleng makin baik, begitupun sebaliknya. Hal ini didukung teori dari (Sihotang, 2006) menyebutkan yang berpengaruhi peningkatan karir ialah masa kerja. Penelitian ini sejalan dengan penelitian (Kristola, 2009) mengemukakan bahwa pengalaman mempunyai pengaruh signifikan terhadap pengembangan karir. Hingga disimpulkan semakin tinggi seorang karyawan memiliki tingkat masa kerja maka akan berdampak kepada peningkatan pengembangan karirnya. Prestasi kerja mempunyai rpengaruh positif terhadap pengembangan karir. Hal ini didukung teori dari Muis (2009) menyatakan bahwa prestasi kerja merupakan faktor yang mempengaruhi pengembangan karir karyawan. Hasil temuan ini didukung atau sejalan dengan riset dari (Labbase, 2010) menyebutkan yakni prestasi krja mempengaruhi peningkatan karir karyawan. Jadi disimpulkan semakin tinggi hasil kerja yang dicapai pegawai maka akan berpengaruh meningkatnya pengembangan karir orang tersebut.

Secara simultan penelitian ini dapat diambil suatu simpulan bahwa ketiga variabel tersebut berpengaruh signifikan terhadap pengembangan karir pegawai. Sejalan oleh teori dari (Sihotang, 2006) yang menyebutkan yang miliki pengaruh 
terhadap pengembangan karir yaitu pendidikan serta pelatihan, pengalaman, dan prestasi kerja. Penelitian ini sejalan juga dengan riset yang menyatakan prestasi kerja, diklat, pengalaman kerja, secara simultan mempunyai pengaruh positif terhadap pengembangan karir pegawai (Jayanti, 2013). Jadi disimpulkan semakin baik ketiga variabel tersebut yang dimiliki karyawan akan berdampak pada peningkatan pengembangan karir karyawan.

\section{SIMPULAN DAN SARAN}

Dapat ditarik beberapa simpulan terkait dengan hasil penelitian ditemukan pengaruh secara parsial dan pengaruh secara simultan pendidikan serta pelatihan, pengalaman, prestasi kerja terhadap pengembangan karir karyawan PDAM Kabupaten Buleleng.

Saran yang dapat penulis berikan pada pihak terkait ialah untuk PDAM Kabupaten Buleleng disarankan pada para atasan dalam membuat kebijakan dalam meningkatkan karir karyawan harusnya perhatikan tiga hal tersebut. Untuk karyawan PDAM Kabupaten Buleleng disarankan agar lebih aktif, kreatif, dan berinisiatif dalam bekerja, terutama bagi karyawan yang kurang mengikuti diklat, prestasi kerja yang kurang sehingga dapat meningkatkan karirnya. Hal ini dilakukan agar karyawan mampu meningkatkan karirnya dan tidak terdapat masalah di masa depan. Dan Bagi peneliti selanjutnya yang tertarik dalam mengkaji terkait peningkatan karir pada sebuah perusahaan dapat dijadikan hasil penelitian ini sebagai referensi, dan manambah wawasan dan pengembangan ilmu untuk penelitian yang lebih maksimal. Selain itu, penelitian ini perlu dikembangkan dan mengkaji faktor lain yang dapat mempengaruhi pengembangan karir karyawan di perusahaan lain.

\section{DAFTAR PUSTAKA}

Foster, B. (2001). Pembinaan Untuk Peningkatan Kinerja Karyawan. Jakarta: PPM.

Gorda. (2004). Manajemen Sumber Daya Manusia. Denpasar: Wirda Kriya Gematama.

Hasibuan, M. (2015). Manajemen Sumber Daya Manusia (Revisi). Jakarta: PT Bumi Aksara.

Jayanti, A. A. S. S. (2013). Pengaruh Prestasi Kerja, Pendidikan, Pengalaman Kerja, Pengenalan dan Kesempatan untuk Tumbuh Terhadap Pengembangan Karir Pegawai Negeri Sipil pada Kantor Dinas Ketentraman Ketertiban dan Satuan Polisi Pamong Praja Kota Denpasar. Jurnal Manajemen Universitas Udayanan, 9(2), 333-367.

Kristola, D. (2009). Pengaruh Diklat dan Pengalaman Kerja Terhadap Prestasi Kerja Serta Dampaknya Terhadap Pengembangan Karir Pegawai Di Balai Karantina Pertanian Kelas 1 Denpasar. Jurnal Manajemen Universitas Udayanan, 8(10), 42-45.

Labbase, I. (2010). Faktor-faktor yang Berpengaruh Terhadap Pengembangan Karir Pegawai Dinas Perikanan dan Kelautan Provinsi Sulawesi Selatan. Jurnal Economic Resources, 11(31), 127-145.

Mangkunegara. (2004). Manajemen Sumber Daya Manusia Perusahaan. Bandung: Remaja Rosdakarya.

Muis, M. (2009). Analisis Faktor-Faktor Yang Mempengaruhi Pengembangan Karir Karyawan Perbankan di Kota Makasar. Jurnal Aplikasi Manajemen, 7(9), 629634.

Sihotang. (2006). Manajemen Sumber Daya Manusia. Jakarta: PT Pradnya Paramitha. 